\title{
Woody biomass and elements uptake in phytoremediation of compost leachate
}

\author{
TOOBA ABEDI ${ }^{1, \bullet}$, NAZI AVANI ${ }^{2, v v}$ \\ ${ }^{1}$ Environmental Research Institute, Academic Center for Education, Culture and Research. Rasht, I.R. Iran. "email: tooba.abedi@gilan.ac.ir, \\ abeditooba@gmail.com \\ ${ }^{2}$ Teaching fellow, School of Distance Education, Universiti Sains Malaysia, Penang, Malaysia. "email: avani.nazi@yahoo.com
}

Manuscript received: 9 May 2018. Revision accepted: 4 June 2018.

\begin{abstract}
Abedi T, Avani N. 2018. Woody biomass and elements uptake in phytoremediation of compost leachate. Asian J For 2: 20-24. The utilization of wastewater for irrigation to develop biomass plantations is a win-win solution to reduce planting costs while mitigating the impacts of waste pollution. This study examined the performance of growth, biomass accumulation and nutrient absorption in Alnus glutinosa and Taxodium distichum treated with leachate water. Randomized research design with three watering treatments, namely tap water as control $(\mathrm{C})$, pure leachate $(\mathrm{P})$ and a mixture 1:1 of tap water and leachate, were applied to one-year-old seedlings of Alnus glutinosa and Taxodium distichum planted in pots. The parameters of diameter and height growth, aboveground and root biomass, and elements uptake were observed for eight months. The results showed that leachate had a positive influence on the growth of A. glutinosa and $T$. distichum in terms of an increase in diameter and height, and aboveground biomass accumulation although there was no significant difference with the other two treatments. This indicated that the irrigations by pure leachate and mixture liquid stimulated growth in the same way as irrigation by water. The results of elements absorption showed no statistical difference except the absorption of $\mathrm{Ca}$ concentration in root which was higher than the absorption of other elements and showed significant difference in 1: 1 treatment. The results of this study suggest that pure compost leachate can be used to water the studied species although further studies that escalate the laboratory scale into field-scale are required.
\end{abstract}

Keywords: Treatment, growth, compost leachate, seedling

\section{INTRODUCTION}

The production of renewable energy sources has been increasingly promoted in Iran including in the form of biomass. In order to achieve this, large-scale planting activities are needed which require sufficient inputs, such as artificial fertilizers, for the optimal growth of biomass crops being developed.

In the development of biomass plantations, fertilizers represent an important production cost. As such, replacement of artificial fertilizers with alternative ones becomes the most favorable option for stakeholders in reducing the cost. There is a win-win solution on the use of fertilizers at minimum cost while reducing the problems of wastes, i.e., using landfill leachate or wastewater from compost production, sludge, etc. (Justin et al. 2010; Holm and Heinsoo 2013). The substitution of artificial fertilizers with waste sources could be a promising option with regard to the reduction of planting costs and simultaneously the reduction of spending on the treatment of wastes.

Previous studies reported positive effects of leachate irrigation on tree growth, showing its fertilizing potential. Zalesny and Bauer (2007b) found that Salix clones S287 and S566 exhibited responses favoring leachate irrigation over water. Justin et al. (2010) detected that the use of landfill leachate treatments resulted in a considerably increased aboveground biomass compared to the control tap water treatment. Further, Abedi et al. (2014, 2015) investigated Populus deltoides, P. euramericana, and Salix alba in phytoremediation, suggesting a potential of pollution removal of wastewater while establishing vegetation.

This paper aimed to investigate the response of Alnus glutinosa and Taxodium distichum to different concentrations of compost leachate with respect to growth and biomass accumulation. The choice of the two species was because of their high biomass production capacity and their status as endemic species of Hyrcanian forests of Iran. Taxodium distichum becomes one of the most well-known conifer trees due to its economic and ecological usefulness. This species also has high tolerance to flooding, waterlogging and salinity (El-Dayem 2003). Alnus glutinosa has tolerance to prolonged submergence of its roots in water for up to $30 \mathrm{~cm}$ deep. This plant can also grow in much drier sites, though, in such conditions, it will usually not live for a long period and will die soon. Alnus can grow well in heavy clay soils, and is in toleration to lime and very infertile sites. It tolerates a wide range of soils but prefers an above $6 \mathrm{pH}$. It is very tolerant to maritime exposure and can grow very rapidly in early stage (http://www.pfaf.org/user/plant.aspx). 


\section{MATERIALS AND METHODS}

\section{Study area and period}

This research was conducted in Safrabaste Poplar Research Station. It is located in eastern part of Gilan province in north of Iran (37 $\left.17^{\circ} \mathrm{N}, 49^{\circ} 57^{\prime} \mathrm{E}\right)$. The experiment was done in growing season in 2013.

One-year-old seedlings of Alnus and Taxodium were used as experiment materials and they were collected from the nursery of the Safrabaste Poplar Research Station. At the beginning of the planting season (i.e., in the middle of March 2013), the seedlings were planted in experiment pots filled with loamy-sandy soil obtained from the surrounding area with a depth of $40 \mathrm{~cm}$. The initial substrate used in the experiment was analyzed in the soil laboratory. In accordance with the standard procedure described by the Soil Science Society of America, the main physical and chemical characteristics of the soil were determined (Page et al. 1982). Table 1 shows a list of substrate analysis, physical characteristics, and analytical methods applied in this study.

Compost leachate was gathered from a leachate reservoir belonging to Compost Plant of Municipal Waste Management of Rasht, North of Iran ( $\left.37^{\circ} 10^{\prime} \mathrm{N}, 4^{\circ} 34^{\prime} \mathrm{E}\right)$. The analysis for its chemical content was performed in the Laboratory of Guilan Department of Environment (Rasht, North of Iran) using approved Standard Methods for the Examination of Water and Wastewater (Eaton et al. 2005).

Table 2 shows the composition of leachate for the experiment. It had dark brown colour with smelly odour. A 20-liter plastic tank was used to store the leachate while it was mixed with tap water to create a mixture with specified degree of dilution. Before filling the tank, chemical analysis of leachate was performed.

In the beginning, tap water was used to water the plants for eight weeks. When the experiment started in mid-May 2013, three watering treatments were applied to the plant, namely: (C) tap water (control), $(\mathrm{P})$ pure leachate, and (1: 1) a mixture of one unit of leachate with one unit of tap water (by volume). The experiment layout was a completely random design consisting of ten replicates for each treatment. The experiment lasted until early December. The pots with the plants inside were placed randomly on an experiment field under a transparent roof to avoid rainfall but still be exposed to sunlight. The plants were irrigated with a mixture of water for as much as the absorption capacity of substrate against water $(0.51$ per pot) in the first week of the experiment. Pure leachate was given without dilution. Tap water for $\mathrm{C}$ treatment and for the preparation of the water mixture is from the public drinking water supply.

The growth in diameter and height of the trees was monitored bi-monthly. The diameter was measured at the breast-high, and the height was recorded from the soil surface to the apical bud at the terminal shoot (Zalesnyet al. 2007a). For eight months of the growth phase, the average growth rate of diameter and height of the trees for each treatment was calculated bi-monthly.
Table 1. Soil chemical and physical properties of the substrate used in the experiment

\begin{tabular}{lll}
\hline Component & Unit & Amount \\
\hline $\mathrm{pH}$ & & 8.31 \\
$\mathrm{EC}$ & $\mathrm{mS} \mathrm{cm}$ & -1 \\
$\mathrm{C}_{\mathrm{org}}$ & $\%$ & 0.128 \\
$\mathrm{~N}_{\text {tot }}$ & $\%$ & 0.08 \\
$\mathrm{P}$ & $\mathrm{mg} \mathrm{kg}-1$ & 0.01 \\
$\mathrm{~K}$ & $\mathrm{mg} \mathrm{kg}^{-1}$ & 0.69 \\
$\mathrm{Ca}$ & $\mathrm{mg} \mathrm{kg}^{-1}$ & 57.60 \\
$\mathrm{Mg}$ & $\mathrm{mg} \mathrm{kg}^{-1}$ & 400 \\
Soil texture & & 24 \\
sand & $\%$ & Loamy sand \\
silt & $\%$ & 86 \\
clay & $\%$ & 5 \\
\hline
\end{tabular}

Table 2. The composition of pure compost leachate

\begin{tabular}{lll}
\hline Parameter & Unit & Amount \\
\hline $\mathrm{pH}$ & $\mathrm{mS} \mathrm{cm}^{-1}$ & 5.22 \\
$\mathrm{EC}$ & $\mathrm{mgL}^{-1}$ & 1.26 \\
$\mathrm{~N}_{\text {tot }}$ & 21.384 \\
$\mathrm{NO}_{2}$ & $\mathrm{mgL}^{-1}$ & 0.08 \\
$\mathrm{NO}_{3}$ & $\mathrm{mgL}^{-1}$ & 21.3 \\
$\mathrm{SO}_{4}$ & $\mathrm{mgL}^{-1}$ & 7101 \\
$\mathrm{PO}_{4}-\mathrm{P}$ & $\mathrm{mgL}^{-1}$ & 22.11 \\
$\mathrm{Na}$ & $\mathrm{mgL}^{-1}$ & 310 \\
$\mathrm{~K}$ & $\mathrm{mgL}^{-1}$ & 250 \\
$\mathrm{Ca}$ & $\mathrm{mgL}^{-1}$ & 152 \\
$\mathrm{Mg}$ & $\mathrm{mgL}^{-1}$ & 1103 \\
$\mathrm{~Pb}$ & $\mathrm{mgL}^{-1}$ & 0.27 \\
$\mathrm{Ni}$ & $\mathrm{mgL}^{-1}$ & 0.342 \\
$\mathrm{Cd}$ & $\mathrm{mgL}^{-1}$ & 0.0047 \\
$\mathrm{Cr}$ & $\mathrm{mgL}^{-1}$ & Trace \\
$\mathrm{COD}$ & $\mathrm{mgL}^{-1}$ & 260500 \\
$\mathrm{BOD}$ & $\mathrm{mgL}^{-1}$ & 130000 \\
$\mathrm{TSS}$ & $\mathrm{mgL}^{-1}$ & 3060.6 \\
Turbidity & $\mathrm{mgL}^{-1}$ & 12500 \\
\hline
\end{tabular}

After eight months, all plants were cut and were separated into two parts, namely: aboveground (stems, branches, and leaves) and root system. The parts of the root system were separated carefully and washed thoroughly with distilled water. Next, the roots and the stems were dried in an oven at $60^{\circ} \mathrm{C}$ for 48 hours. The biomass and absorbed elements of aboveground and of root were calculated carefully. Data were calculated using SPSS 16.0 statistical package. The statistical dissimilarity among treatments is ascertained by the analysis of variance. The outcomes were regarded significant at $p<0.05$. The tree growth rate was displayed on graphs of the diameter and of height against time. The test of Tukey was applied to get the dissimilarity between level means.

\section{RESULTS AND DISCUSSION}

High quantity of chemical contents was given to plants in the pots. The contents of $\mathrm{N}, \mathrm{P}$ and $\mathrm{K}$ were much greater in the leachate than in the soil, but $\mathrm{Ca}$ content was lower 
compared to that in soil-filled in the pots. The higher ion concentration in leachate also reflected higher electrical conductivity $\left(1.26 \mathrm{mS} \mathrm{cm}^{-1}\right)$ compared to that in soil $(0.128$ $\left.\mathrm{mS} \mathrm{cm}{ }^{-1}\right)$. Metal contents were low in the leachate. After eight months, pure leachate treatment $(\mathrm{P})$ showed the highest diameter growth of $A$. glutinosa and $T$. distichum with an average of 1.356 and $1.128 \mathrm{~cm}$ respectively (Figure 1). In terms of height, a higher rate of growth was found in the treatment of pure leachate $(\mathrm{P})$ and a mixture of leachate and water (1:1) (Figure 2). Nonetheless, all three treatments have no significant differences in terms of the growth in diameter and height for both species (Figures 3 and 4).

The greatest accumulation of aboveground biomass was obtained in the treatment of $1: 1$, but it was not significantly different from other treatments $(\mathrm{p}<0.05)$ (Figure 5). For root biomass, the greatest accumulation was in the treatment of 1:1, which was not significantly different from the treatment of $\mathrm{C}$, but gave a significant difference from $\mathrm{P}$ treatment $(\mathrm{p}<0.05)$ (Figure 6).

The outcome of elements absorption shows no statistical differences among treatments and across species. Lower $\mathrm{K}$ absorption was found on the control (C) treatment while the most absorption of $\mathrm{Ca}$ happened above ground (Figure 7). The absorption of $\mathrm{Ca}$ concentration on root was higher than the absorption of other elements and show significant difference in 1:1 treatment (Figure 8).

\section{Discussion}

The positive effects of leachate irrigation on tree growth and its fertilizing potential for plants have been reported by many studies. Justin et al. (2010) found that the utilization of landfill leachate treatment increased the amount of surface biomass significantly compared with the control tap water treatment, but tree growth and biomass accumulation in wastewater compost treatment decreased compared to the treatment of tap water and compost leachate. The results of Abedi et al. $(2014,2015)$ showed a positive effect of compost leachate on tree species. Depend on the constituents of the leachate and soil, as well as the nutrient demands of the genotypes tested, the concentrations and amounts of leachate can be determined (Zalesny and Bauer 2007b).

In all treatments, no statistically significant differences in the aboveground biomass were found (Figure 5). High concentration in the pure leachate $(\mathrm{P})$ treatment turned out to be toxic, meaning that the water mixture in $\mathrm{P}$ treatment already had too high concentration of salts and other elements (Table 2).

The compost leachate was a by-product of composting of organic matter, having a low $\mathrm{pH}$ (5.22) which is a sign of unfinished degradation processes of raw organic matter, where due to the inadequate oxygen levels. The comparison of the plant growth in the several treatments showed apparently normal and healthy-looking trees.

The nitrogen content was also elevated in compost leachate. There is acknowledged in common agricultural practice that supplementary nitrogen is utilized to manage distinctive toxicity issues and boost vegetation growth (Ayers and Westcot 1994). Kadlec and Wallace (2009) notified that more elevated concentrations of sulfate (402 $\mathrm{mg} \mathrm{SO}_{4} / \mathrm{L}$ ) in compost leachate could bring negative effect on plant absorption in water-saturated root part and should also be highlighted. In this study, the sulfate concentration was $7101 \mathrm{mg} \mathrm{SO} / \mathrm{L}$. Still, the plant continued to accrue.
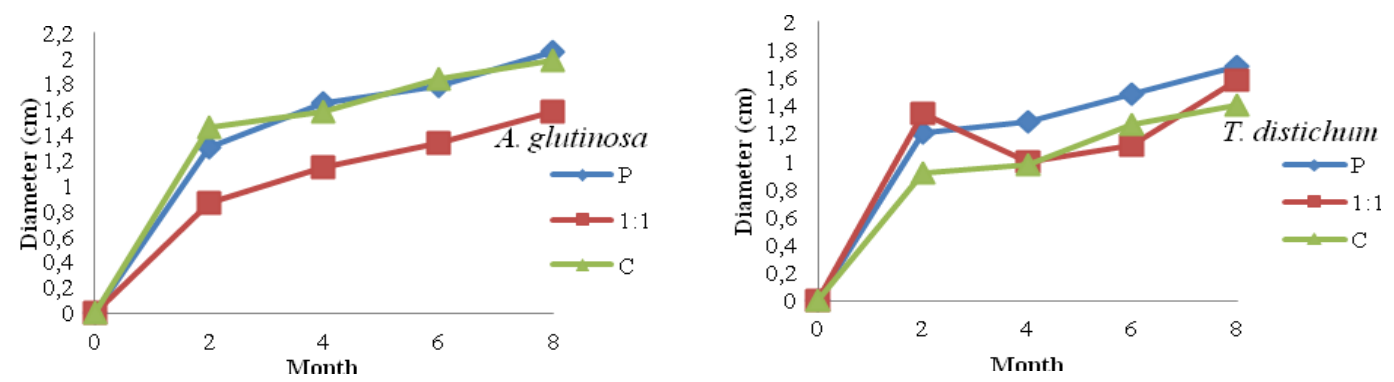

Figure 1. Mean growth in diameter $(\mathrm{cm})$ of Alnus glutinosa and Taxodium distichum with three watering treatments
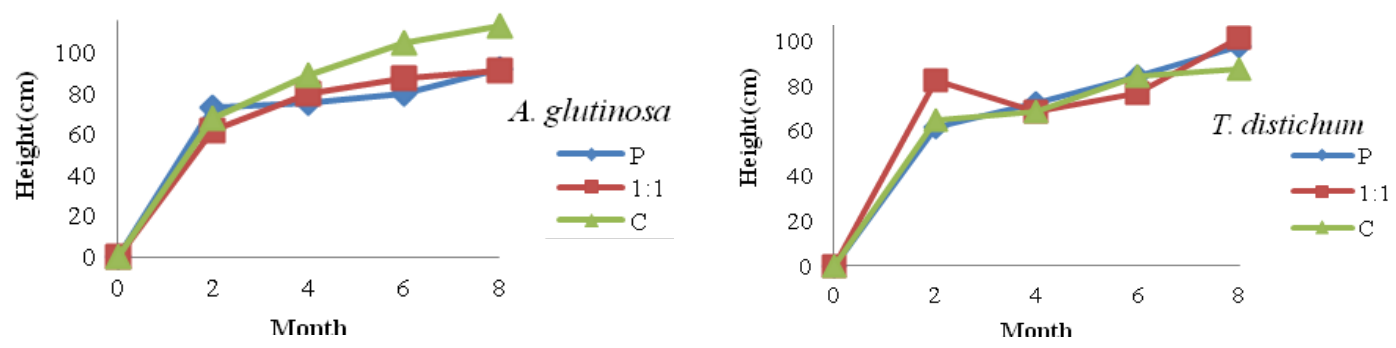

Figure 2. Mean growth in height (cm) of Alnus glutinosa and Taxodium distichum with three watering treatments 


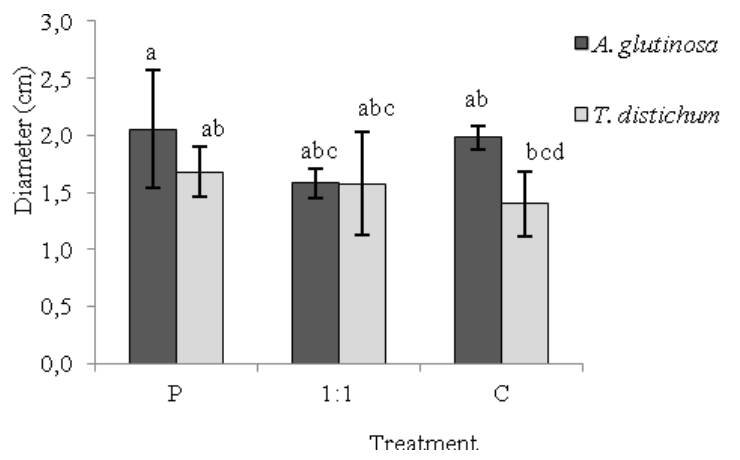

Figure 3. Comparison of mean of diameter in all treatments. Note: bars with similar letters indicate no significant differences at the level of confidence of $95 \%$

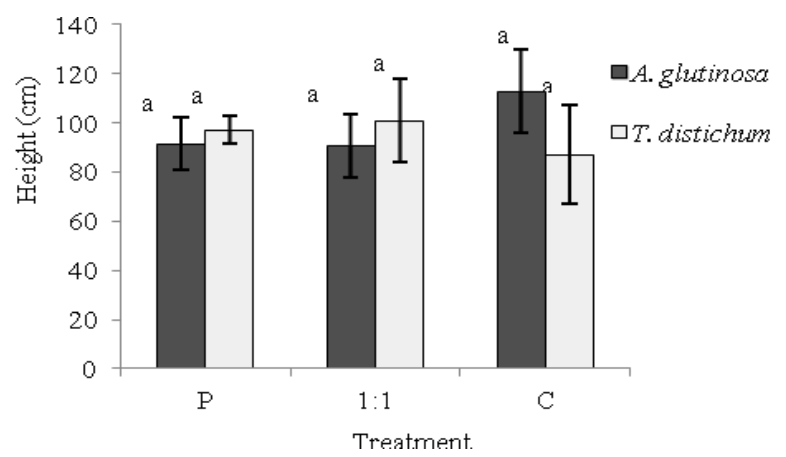

Figure 4. Comparison of mean of height in all treatments. Note: bars with similar letters indicate no significant differences at the level of confidence of $95 \%$

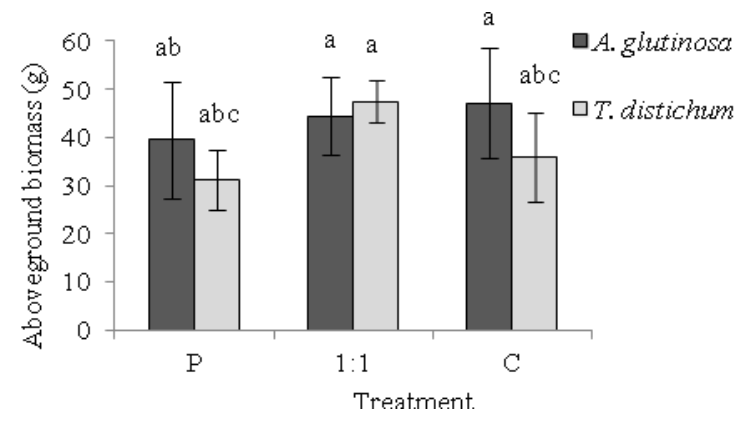

Figure 5. Comparison of mean of aboveground biomass components. Note: bars with similar letters indicate no significant differences at the level of confidence of $95 \%$

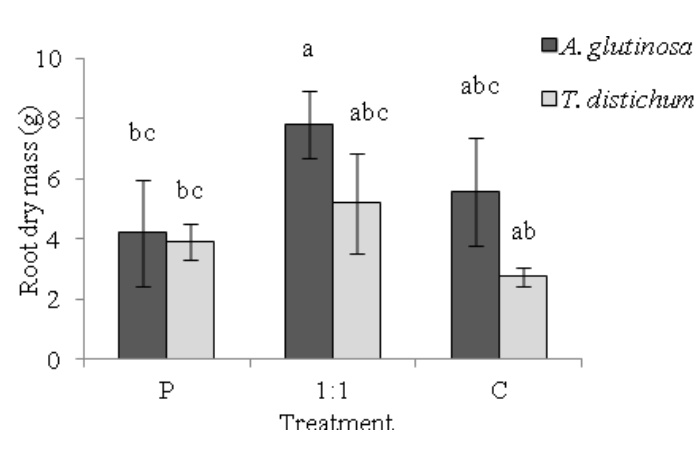

Figure 6. Comparison of mean of root biomass components. Note: bars with similar letters indicate no significant differences at the level of confidence of $95 \%$

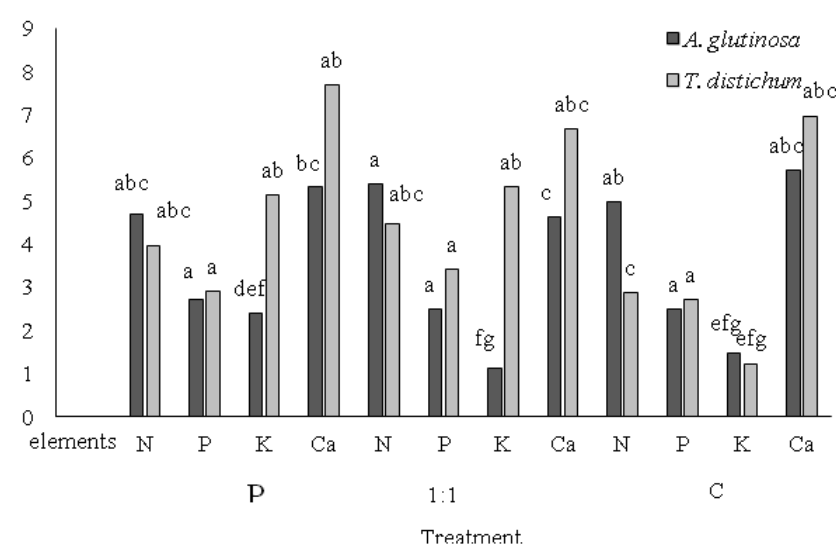

Figure 7. Comparison of aboveground elements uptake. Note: bars with similar letters indicate no significant differences at the level of confidence of $95 \%$

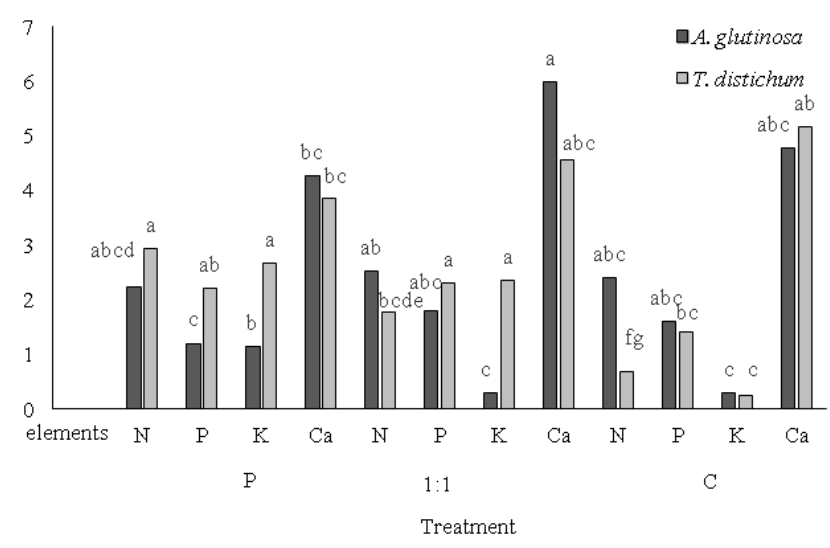

Figure 8. Comparison of root elements uptake. Note: bars with similar letters indicate no significant differences at the level of confidence of $95 \%$ 
Fung et al. (1998) and Abedi et al. (2014) stated that elevated rates of salt $(1.0 \% \mathrm{NaCl})$ quickly lessened the absorption of Populus and owned an instantaneous result on predawn leaf water potency, photosynthesis and stomatal resistance. It has been notified that the Populus was sensitive to salt, but $A$. glutinosa which was hardwood tree species and $T$. distichum which was softwood tree species have no negative reactions to elevated concentrations of salts.

Zalesny and Bauer (2007b) used fast-accretion Populus and Salix clones and their genomic groups to be treated with waste leachate for one growing season. In such experiment, Populus resulted greatest in diameter and dry mass. The highest level of phytoremediation showed no significant relation with the highest biomass yield (Greger and Landberg 1999; Klang-Westin and Eriksson 2003; Zalesny and Bauer 2007b), and the concentration of iron and nutrients is piled up in the bark which is higher than the wood tissue (Pulford and Dickinson 2005; Dimitriou et al. 2006; Adler et al. 2008). This should be examined in the future elemental analysis of the plant material.

The results of this study suggest that pure compost leachate can be used to water the studied species. However, upscaling the experiment to the field would enable leaching of the excess water from the root zone, and the washing-out of salts by precipitation to the lower soil layers, thus better survival with the same amounts of pure compost leachate as used in the pot experiment. The development of aboveground biomass is important from the leachate consumption and phytoremediation point of view (Justin et al. 2010).

\section{ACKNOWLEDGEMENTS}

We would like to thank Afshin Azizi (Head of the Natural Disaster Control and Management Center of Guilan Province) for their financial support and Safrabaste Poplar Research Station for their technical-scientific supports.

\section{REFERENCES}

Abedi T, Moghddami Sh, Laskar Bolouki E. 2014. Growth of Populus and Salix species under compost leachate irrigation. Ecologia Balcanica 6 (2): $57-65$
Abedi T, Moghddami Sh. 2015. Phytoremediation concept: Biomass production and growth of Populus deltoides under compost leachate irrigation, J For Sci 61 (6): 250-254. DOI: 10.17221/121/2014-JFS .

Adler A, Dimitriou I, Aronsson P, VerwijstT, Weih M. 2008. Wood fuel quality of two Salix viminalis stands fertilised with sludge, ash and sludge-ash mixtures. Biomass Bioenerg 32 (10): 914-925. DOI: 10.1016/j.biombioe.2008.01.013.

Ayers RS, Westcot DW. 1994. Water Quality for Agriculture. FAO, Rome.

Dimitriou I, Aronsson P, Weih M. 2006. Stress tolerance of five willows clones after irrigation with different amounts of landfill leachate. $\begin{array}{llll}\text { Bioresource } & \text { Technol 97: } & 150-157 . & \text { DOI: }\end{array}$ 10.1016/j.biortech.2005.02.004

Eaton AD, American Public Health Association, American Water Works Association, Water Environment Federation. 2005. Standard Methods for the Examination of Water and Wastewater. American Public Health Association: 1325, Washington, D.C.

El-Dayem A. 2003. Effect of Fertilizer Treatments on Taxodium distichum Seedlings Grown in Alkali Soil. XII World Forestry Congress. 21-28 September 2003, Quebec City, Canada.

Fung LE, Wang SS, Altman A, Hu"tterman A. 1998. Effect of $\mathrm{NaCl}$ on growth, photosynthesis, ion and water relations of four poplar genotypes. For Ecol Manag 107: 135-146. DOI: 10.1016/S03781127(97)00328-9.

Greger M, Landberg T. 1999. Use of willow in phytoextraction. Intl J Phytoremed 1: 115-123. DOI: 10.1080/15226519908500010.

Holm B, K. Heinsoo. 2013. Influence of composted sewage sludge on the wood yield of willow short rotation coppice. Environ Protect Eng 39 (1): 17-32.

Justin MZ, PajkN, Zupanc V, Zupancic M. 2010. Phytoremediation of landfill leachate and compost wastewater by irrigation of Populus and Salix: Biomass and growth response. Waste Manag 30: 1032-1042. DOI: 10.1016/j.wasman.2010.02.013

Kadlec RH, Wallace SD. 2009. Treatment Wetlands, 2nd ed. CRC Press, Boca Raton, FL.

Klang-Westin E, J. Eriksson. 2003. Potential of Salix as phytoextractor for Cd on moderately contaminated soils. Plant Soil 249: 127-137. DOI: 10.1023/A:1022585404481.

Navarro JM, Tornero OP, Morte A. 2014. Alleviation of salt stress in citrus seedlings inoculated with arbuscular mycorrhizal fungi depends on the rootstock salt tolerance. J Plant Physiol 171: 76-85. DOI: 10.1016/j.jplph.2013.06.006.

Page AL, Miller RH, Keeney DR. 1982. Methods of Soil Analysis. Part 2, Chemical and Microbiological Properties. American Society of Agronomy, Inc. Soil Science of America, Inc. Madison, Wisconsin, USA.

Pulford ID, Dickinson NM. 2005. Phytoremediation technologies using trees. In: Prassad MNV, Naidu R (eds.). Trace Elements in the Environment. CRC Press, New York, USA.

Zalesny JA, Zalesny RSJr, Coyle DR, Hall RB. 2007. Growth and biomass of Populus irrigated with landfill leachate. For Ecol Manag 248: 143-152. DOI: 10.1016/j.foreco.2007.04.045.

Zalesny RSJr, Bauer OE. 2007. Selecting and utilizing Populus and Salix for landfill covers: Implications for leachate irrigation. Intl $\mathbf{J}$ Phytoremed 9: 497-511. DOI: 10.1080/15226510701709689. 